\title{
Prevalence of anogenital HPV infection, related disease and risk factors among HIV- infected men in inner-city Johannesburg, South Africa: baseline findings from a cohort study
}

Admire Chikandiwa ${ }^{1 *}$, Lucy Chimoyi ${ }^{1}$, Pedro T Pisa ${ }^{1}$, Matthew F Chersich ${ }^{1}$, Etienne E Muller ${ }^{2}$, Pamela Michelow ${ }^{2,3}$, Philippe Mayaud ${ }^{1,4}$ and Sinead Delany-Moretlwe ${ }^{1}$

\begin{abstract}
Background: Persistent high-risk human papillomavirus (HR-HPV) infection is associated with the development of anogenital cancers, particularly in men living with HIV (MLWH). We describe the prevalence of anogenital HPV infection, abnormal anal cytology and anogenital warts (AGWs) in MLWH in Johannesburg, and explore whether HPV infection and receipt of antiretroviral treatment is associated with detection of abnormal anal cytology and AGWs.
\end{abstract}

Methods: We enrolled a cohort of 304 sexually-active MLWH $\geq 18$ years, who completed a questionnaire and physical examination. Genital swabs were collected from all men and intra-anal swabs from 250 (82\%). Swabs were tested for HPV DNA and genotypes, and anal smears graded using the Bethesda classification. Factors associated with anogenital disease were assessed by logistic regression models.

Results: Two thirds were receiving antiretroviral treatment, for a median 33 months (IQR $=15-58)$ and $54 \%$ were HIV-virologically suppressed. Only 5\% reported ever having sex with men. Among 283 genital swabs with valid results, 79\% had any HPV, 52\% had HR-HPV and 27\% had >1 HR-HPV infection. By comparison, 39\% of the 227 valid intra-anal swabs had detectable HPV, 25\% had any HR-HPV and 7\%>1 HR infection. While most anal smears were normal (51\%), 20\% had ASCUS and 29\% were LSIL. No cases had HSIL or cancer. Infection with $>1$ HR type (adjusted $\mathrm{OR}[\mathrm{aOR}]=2.39 ; 95 \% \mathrm{Cl}=1.02-5.58)$ and alpha-9 types $(\mathrm{aOR}=3.98 ; 95 \% \mathrm{Cl}=1.42-11.16)$ were associated with having abnormal cytology. Prevalence of AGWs was $12 \%$. Infection with any LR type $(a \mathrm{O}=41.28 ; 95 \% \mathrm{Cl}=13.57-125.62)$, $>1$ LR type $(\mathrm{aOR}=4.14 ; 95 \% \mathrm{Cl}=1.60-10.69)$, being $<6$ months on antiretroviral treatment $(\mathrm{aOR}=6.90 ; 95 \% \mathrm{Cl}=1.63-29$. 20) and having a CD4+ count $<200$ cells/ $\mu \mathrm{L}(\mathrm{aOR}=5.48 ; 95 \% \mathrm{Cl}: 1.60-18.78)$ were associated with having AGWs.

Conclusions: In this population, anogenital HR-HPV infection and associated low-grade disease is common, but severe anal dysplasia was not detected. Findings reinforce the need for HPV vaccination in men for preventing both AGWs and HR-HPV infection. Given the absence of anal HSILs, however, the findings do not support the use of anal screening programmes in this population.

Keywords: Anogenital infection, Human papillomavirus, Anogenital warts, Anal cytology, HIV, Men, South Africa

\footnotetext{
* Correspondence: achikandiwa@wrhi.ac.za

'Wits Reproductive Health and HIV Institute (WRHI), Faculty of Health

Sciences, University of the Witwatersrand, Johannesburg, South Africa

Full list of author information is available at the end of the article
} 


\section{Background}

Anogenital human papillomavirus (HPV) is the most frequent sexually transmitted infection (STI) in the world, in both men and women [1,2]. The burden of anogenital HPV infections in men, as measured by HPV DNA prevalence, ranges widely, from estimates of 2 to 84\% [3]. Anogenital HPV is classified into highrisk (HR) types, that are implicated in men in the evolution of anal and penile cancers, and low-risk (LR) types which are largely associated with the development of anogenital warts (AGWs) [4]. An estimated $20-30 \%$ of men with anogenital HPV infection are reported to develop persistent HPV infection that can progress to anogenital cancers and/or warts $[5,6]$. Persistent infection with the HR types 16 and 18 is believed to be responsible for at least $80 \%$ of anal cancer cases and its precursor, anal intraepithelial neoplasia (AIN) $[7,8]$. The LR-HPV types 6 and 11 are the predominant cause of AGWs $[9,10]$. While AGWs are benign, they are a source of psychosocial distress [11] and can cause physical discomfort, including bleeding and itching [12]. Approximately $25 \%$ of AGWs will spontaneously regress [12], however, recurrence is common, resulting in high medical costs from repeated treatment [13].

Although data for men in sub-Saharan Africa (SSA) are limited, overall reported anogenital HPV DNA prevalence is high, ranging from 19 to $78 \%$ [14-19]. The incidence of anogenital HR-HPV infection in men in South Africa is also concerning, averaging 40 per 100 person-years [20-22]. HIV may alter the susceptibility to, and natural history of, HPV-associated diseases [23, 24]. Men living with HIV (MLWH) are at increased risk for prevalent anogenital HPV infection and anogenital cancers, regardless of sexual behaviour [24, 25]. There is evidence that AGWs in immunocompromised MLWH have a prolonged clinical course $[26,27]$. This is in part attributed to immune dysfunction which impairs immunosurveillance and clearance of viral infections such as HPV $[24,28]$. While data suggest that the progression of AIN disease is less predictable than cervical cancer with some AIN lesions spontaneously regressing, [6] ART does not appear to reverse the risk for anal cancer once AIN is identified [29].

A number of strategies have been proposed to reduce anogenital HPV infection and its associated burden of disease in men. Screening for AIN using anal cytology has been recommended in some high-income countries [30]. However, the benefits for screening for AIN in lowto middle-income countries (LMICs), such as South Africa, are uncertain. HPV vaccines, used as primary prevention, have been shown to be efficacious in women, and vaccine studies have now demonstrated evidence of benefit in men [31].
While HPV vaccination programmes for girls residing in LMICs have scaled up [32], questions remain about whether to include boys or to target vaccination to highrisk groups of women and men, such as MLWH. Decisions about vaccination in $\mathrm{MLWH}$, who constitute a large population in many LMICs, are contingent on the epidemiology of HPV infection and related disease in men [33]. Using data collected from MLWH who were recruited into a cohort in inner-city Johannesburg, we estimated the prevalence of anogenital HPV infection and associated anogenital disease, as well as the uptake of anal canal swabbing. We further examined the relationships between HPV infections, antiretroviral treatment, CD4 count and HIV viral load, and the presence of either abnormal anal cytology or AGWs. Finally, we explored the implications of the study findings for HPV prevention.

\section{Methods}

\section{Study design, setting and population}

We analysed baseline data from MLWH enrolled in a prospective cohort study. The primary aim of the cohort study was to evaluate the natural history of HPV infection and disease in HIV-infected men in South Africa to help inform the selection of HPV prevention interventions in this population, such as primary or secondary HPV vaccination, and anal screening. In inner-city Johannesburg, between October 2012 and August 2013, men in the community or attending HIV clinics were approached and asked to volunteer for the study. Potential participants were screened for eligibility and enrolled if they were willing to provide informed consent, 18 years or older, reported at least one episode of sexual intercourse in the past 3 months and were HIV positive on rapid testing. All procedures were conducted at a research clinic in downtown Johannesburg.

\section{Questionnaire administration and clinical procedures}

Participants were interviewed by male nurses using a structured questionnaire that covered socio-demographic, medical and behavioural characteristics. For questions on sensitive topics, participants were given a tablet computer to self-complete data collection. The participants, all of whom had completed at least a primary education, were given a demonstration from the research nurse on how to use the tablet. A nurse or doctor conducted a physical examination to determine the presence of AGWs and circumcision status. The anatomical location of warts was marked on a diagram of the genitalia. Digital rectal examination was performed on all participants to exclude gross abnormalities. One participant with a palpable abnormality was referred to a colorectal surgeon for further assessment and management. The final diagnosis was anal warts. Blood samples were then collected and 
stored at $8{ }^{\circ} \mathrm{C}$ before testing for $\mathrm{CD} 4+$ count and HIV plasma viral load (PVL). Participants who had a CD4+ count $<350$ cells $/ \mu \mathrm{L}$ were referred to an HIV clinic for ART initiation, in accordance with the national guidelines at the time [34].

Clinicians were trained in intra-anal swab collection by a colorectal surgeon; competency was established in practical sessions that involved ten men. Smears collected during the training sessions were subsequently assessed by a cytopathologist at the National Health Laboratory Service (NHLS) as having adequate cellular material for analysis.

Genital HPV DNA was assessed on a cotton swab that was rubbed gently, but firmly, around the glans penis, coronal sulcus, and then down the ventral surface of the penis and the scrotum [35]. Two intra-anal swabs were collected by blindly inserting a saline-moistened dacron swab $3 \mathrm{~cm}$ into the anal canal, and then removing it whilst rotating the swab and applying gentle pressure on the walls of the canal [4]. One intra-anal swab was used for HPV DNA testing, while the other was used to prepare a conventional anal smear for cytological analysis, by rolling the swab on a glass side and then fixing it with cytological fixative spray. Participants were informed that they could opt out of any procedures they felt uncomfortable with. Swabs were stored at $-70{ }^{\circ} \mathrm{C}$ before testing.

\section{Laboratory testing}

HIV status was assessed by two rapid tests (Alere Determine $^{\mathrm{Tm}} \mathrm{HIV}-1 / 2$ [Alere International Limited, Galway, Ireland] and Uni-Gold ${ }^{\text {mix }}$ Recombigen HIV-1/2 [Trinity Biotech PLC, Co. Wicklow, Ireland]), in accordance with national guidelines [36]. Among those that tested positive, CD4+ count was measured using FACScount, $\mathrm{BD}^{\mathrm{Tm}}$ (BD Biosciences, United States). HIV RNA was assessed by Roche Taqman (Roche Diagnostics, Mannheim, Germany).

Identical methods of HPV testing were used for genital and intra-anal swabs. DNA was extracted from swabs using the MagNA Pure LC DNA Isolation Kit I in combination with the MagNA Pure LC 2.0 automated nucleic acid extractor (Roche Diagnostics, Mannheim, Germany). Thereafter, HPV genotype distributions were assessed using the Roche Linear Array (Roche Diagnostics, Mannheim, Germany). The GeneAmp 9700 PCR System (Roche Diagnostics, Mannheim, Germany) was used to amplify the target HPV DNA for 37 anogenital HPV genotypes, including both LR HPV types $(6,11,26,40,42,53,54,55,61,62,64$, $66,67,69,70,71,72,73,81,82,83,84$, IS39 and CP6108) and HR HPV types (16, 18, 31, 33, 35, 39, 45, 51, 52, 56, 58, 59 and 68). HR HPV types were defined using the current International Agency for Research on
Cancer (IARC) classification [37]. The assay included a $\beta$-globin human gene target to control for cell adequacy, extraction and amplification. All procedures were performed in accordance with manufacturer's instructions.

Conventional anal smears were examined as a single batch at the end of the study. Anal smears were stained by the Papanicolaou stain before being analysed and classified according to the Bethesda System (liquid-based cytology is not available within the South African public health care system and thus was not used) [38]. Smears were graded as either unsatisfactory for analysis, negative for intraepithelial malignancy (NILM), atypical squamous cells of undetermined significance (ASCUS), atypical squamous cells-high grade lesions cannot be ruled out (ASC-H), and low- (LSIL) or high-grade squamous intraepithelial lesions (HSIL). Smears were read independently by a cytotechnologist and one cytopathologist at the NHLS in Johannesburg. If there was a discrepancy between these two readings, the smear was given to a second cytopathologist. Grade ASCUS or higher was considered abnormal.

\section{Study variables and analysis}

Participants reporting always using a condom with their most recent partner were classified as consistent condom users. MLWH were defined as having controlled HIV disease if they had been receiving ART for at least 6 months, an undetectable PVL (plasma HIV RNA $<40$ copies/ml) and a CD4+ count greater than 350 cells $/ \mu \mathrm{L}$. Two additional variables for HPV infection were created, namely: any alpha-7 category (HPV types 18, 39, 45 and 59); any alpha-9 category (HPV types 16, 31, 33, 35, 52 and 58). To assess uptake of anal swabbing, participants were specifically asked if they were willing to have anal swabbing before the intra-anal swabs were taken and the response was noted on the study case report form.

Data were summarized using frequencies, means (standard deviation [SD]), or medians (interquartile range [IQR]). Student $t$ and Mann-Whitney tests for continuous variables and chi-squared tests for categorical variables were used to detect differences in characteristics between those with and without HPV DNA. Logistic regression models were used to explore whether HPV infection status and antiretroviral treatment status, CD4 count and HIV viral load were associated with having the two HPV disease outcomes (any anal cytological abnormality and AGWs). The following three models were computed, M1: bivariate (crude); M2: adjusted for age; and M3 adjusted for age, CD4+ count, duration on ART, circumcision status (for AGWs only) and marital status (for abnormal cytology only) [39, 40]. All analyses were performed in Stata ${ }^{\mathrm{mm}}$ Version 12 [41]. 


\section{Results}

\section{Participant characteristics}

A total of 304 men with a mean age of 38 years (SD, 8 years) were enrolled between March 2011 and October 2012 (Table 1). The majority of participants were born in South Africa (68\%) and unmarried (59\%), with 25\% reporting more than one sexual partner in the previous 3 months. Only 5\% $(n=15)$ reported ever having sex with other men. Of these, 10 reported that they were MSM and had had receptive anal sex, while the other 5 had never had receptive anal sex. A third (31\%) were cigarette smokers and $20 \%$ circumcised. Most participants $(65 \%)$ were already taking ART $(n=197)$, for a median duration of 33 months (IQR, 15-58). Among those on ART, $54 \%$ were virologically suppressed, with a median CD4+ count of 445 cells/ $\mu \mathrm{L}$ (IQR, 328-567) and only $9 \%$ had a CD $4+$ count $<200$ cells $/ \mu \mathrm{L}$.

\section{Prevalence of HPV infection}

All 304 participants provided genital swabs. HPV DNA of any type was detected in 224 of the 283 valid genital swab samples (79\%; Figure 1). Aside from being born in South Africa (71\%), no other differences were detected in the characteristics of men with and without HPV DNA (Table 1). The median number of infections detected per genital swab was 2.0 (IQR, 1.0-4.0). HR-HPV was detected in 52\% $(n=147)$ of samples. HPV 16 and 35 were the most frequently detected HR-HPV types (13\% of men), and 18\% had an HPV 16 and/or HPV 18 infection (51/283). Multiple HR-HPV infections (76/ 283) were observed in more than a quarter of men (27\%), and $35 \%(51 / 147)$ of HR-HPV infections could be attributed to types 16 or 18 . LR-HPV infections were more common than HR-HPV $(64 \%, n=182, p=0.05)$ and $38 \%(108 / 283)$ of men had multiple LR-HPV infections. Among the men with LR-HPV, 16 (9\%) also had at least one HR-HPV infection. The commonest LRHPV types observed were types 62 (11\%), 6 (10\%) and $84(10 \%)$.

The uptake of anal swabbing was high, with $82 \%$ (250/304) of men agreeing to the procedure. Of the 250 swabs taken, 227 had valid results (91\%) and

Table 1 Characteristics of participants, by genital HPV DNA status

\begin{tabular}{|c|c|c|}
\hline Characteristic & $\begin{array}{l}\text { HPV DNA detected } N=224 \\
\mathrm{n}(\%) \text { or Mean (SD) or Median (IQR) }\end{array}$ & $\begin{array}{l}\text { Total } N=304 \\
\mathrm{n}(\%) \text { or Mean (SD) or Median (IQR) }\end{array}$ \\
\hline Age, mean years & $38(8)$ & $38(8)$ \\
\hline Born in SA & $161(71)^{*}$ & $208(68)$ \\
\hline Single & $136(60)$ & $180(59)$ \\
\hline Employed & $159(71)$ & $214(71)$ \\
\hline Currently smokes & $75(33)$ & $94(31)$ \\
\hline Currently drinks alcohol & $122(54)$ & $161(53)$ \\
\hline Mean age at sexual debut & $18(3)$ & $17(3)$ \\
\hline Ever had sex with men & $10(4)$ & $15(5)$ \\
\hline$>1$ sexual partner in past 3 months & $53(23)$ & $77(25)$ \\
\hline Consistent condom use with recent partner & $143(63)$ & $190(63)$ \\
\hline On ART & $144(63)$ & $197(65)$ \\
\hline Duration on ART, median months & $31(13-55)$ & $33(15-58)$ \\
\hline CD4+ count, median cells/ $\mu \mathrm{L}(n=288)$ & $443(327-556)$ & $445(328-567)$ \\
\hline Undetectable PVL (<40 copies/ml) & $83(39)$ & $107(54)$ \\
\hline Circumcised & $43(19)$ & $62(20)$ \\
\hline Anogenital warts present & $36(16)^{*}$ & $36(12)$ \\
\hline Accepted intra-anal swabbing & $160(70)$ & $250(82)$ \\
\hline HPV detected on intra-anal swab $(n=227)$ & $84(37)$ & $88(39)$ \\
\hline \multicolumn{3}{|l|}{ Anal cytology results $(n=242)^{a}$} \\
\hline NILM & $94(41)$ & $123(51)$ \\
\hline ASCUS & $37(16)$ & $48(20)$ \\
\hline LSIL & $50(22)$ & $70(29)$ \\
\hline HSIL & $0(0)$ & $0(0)$ \\
\hline
\end{tabular}

Of 304 genital swabs sent for analysis, 21 had invalid results. *: $p$-value $<0.05$ for comparison of those with and without genital HPV infection. PVL, plasma viral load among those on antiretroviral therapy (ART). ${ }^{a} 250$ smears were sent for analysis, 8 had invalid results. NILM Negative for intraepithelial malignancy. ASCUS Atypical Squamous Cells of Undetermined Significance. LSIL Low-grade Squamous Intraepithelial Lesion. HSIL High-grade Squamous Intraepithelial Lesion 


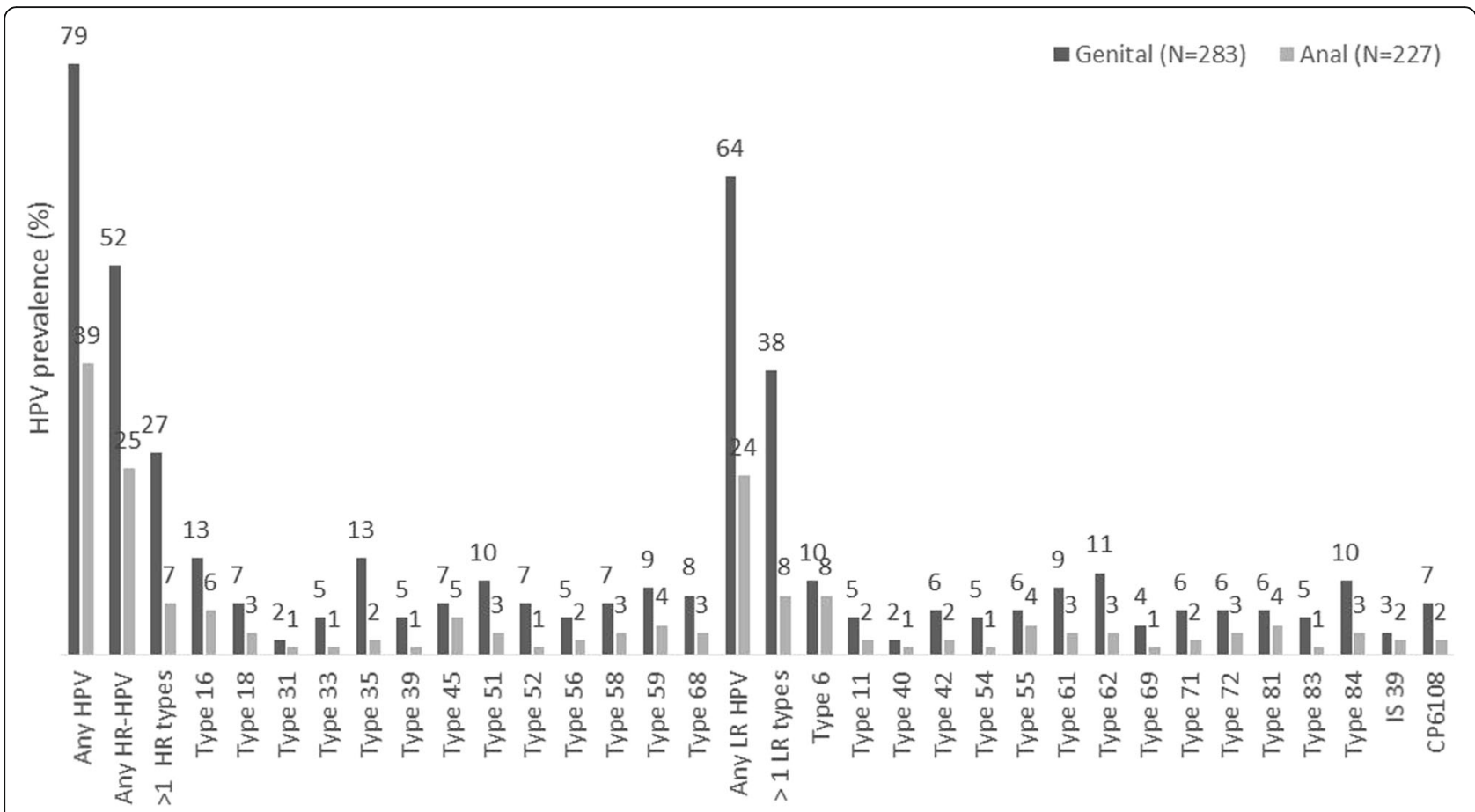

Fig. 1 Prevalence of HPV infection by anatomical site

HPV DNA was detected in 39\% $(n=88)$ of them (Figure 1). In contrast to the genital swabs, the prevalence of HR-HPV infection in the anal canal (25\%) was comparable to that of LR-HPV (24\%) detected in these swabs. Fewer men had either multiple HR-HPV type $(7 \%)$ or LR-HPV type $(8 \%)$ infections in the anal canal compared to the genital swabs. Of the HR-HPV types, the most commonly detected types were $16(6 \%), 45(5 \%)$ and $59(4 \%)$. Among all HR-HPV infections detected in the anal canal $(n=56), 43 \%$ were type 16 or 18 . HPV types $6(8 \%)$, $55(4 \%)$ and $81(4 \%)$ were the most common LRHPV types detected. Together types 6 or 11 made up $46 \%(25 / 54)$ of all LR-HPV infections detected in the anal canal.

Results of both genital and anal swabs were available for 227 men, of these only $1 \%(n=3)$ had no HPV infection, 58\% $(n=132)$ had HPV infection of the genitalia only, $4 \%(n=8)$ anal canal only and $37 \%(n=84)$ had infection of both sites. A total of 168 men had an HRHPV infection (either genital or anal canal), of these $33 \%$ had infection in both sites. Corresponding figures for LR-HPV were 177 and 29\%. In terms of HPV genotypes among the 227 men with valid genital and anal swab results, the number who were infected with the same genotype in both sites (n) of all men with the genotype (N) were (i) HPV 16 (8/38) [21\%] (ii) HPV 18 $(2 / 21)$ [10\%] (iii) HPV 6 (9/44) [21\%] and (iv) HPV 11 $(3 / 23)$ [13\%].

\section{Prevalence and factors associated with abnormal anal cytology}

Valid cytological results were available for 242 of the 250 anal smears (Table 1). Abnormalities were detected in half of the smears (49\%). Among those with abnormal anal cytology results, 20\% were graded as ASCUS and $29 \%$ as LSIL. No cases of ASC-H, HSIL or invasive cancer were detected. HR-HPV was detected more frequently in LSIL than in ASCUS (21\% vs. 15\%; Figure 2). In LSIL cases, type 16 was most prevalent $13 \%(n=9)$, this was followed by, in order of decreasing frequency, HPV 45 (9\%), HPV 59 (7\%), HPV 18 (6\%), HPV 68 (6\%), HPV 31, 33, 35 \& 58 all at 4\%, HPV 51 \& 56 all at 3\%, and HPV 52 (1\%). HPV 39 was not detected in this group (Additional file 1: Table S1).

We explored whether ART, participant's health status and different HPV infections were associated with abnormal anal cytology (Table 2 and Additional file 2: Table S2). Current ART use was associated with an increased odds of abnormal anal cytology in models adjusting for age (adjusted $\mathrm{OR}=2.26$; $95 \% \mathrm{CI}=1.26$ 4.09; $p=0.007$ ), while associations were not detected between abnormalities, and time since ART initiation, current CD4+ count and PVL. Intra-anal HPV infection was associated with abnormal anal cytology (Additional file 2: Table S2). Infection with more than one HR type $(\mathrm{aOR}=2.39 ; 95 \% \mathrm{CI}=1.02-5.58 ; p=0.04)$, and any alpha-9 types $(\mathrm{aOR}=3.98 ; 95 \% \mathrm{CI}=1.42-11.16$; $p=0.01$ ) were strongly linked with an increased risk of 
$(\mathrm{N}=242)$

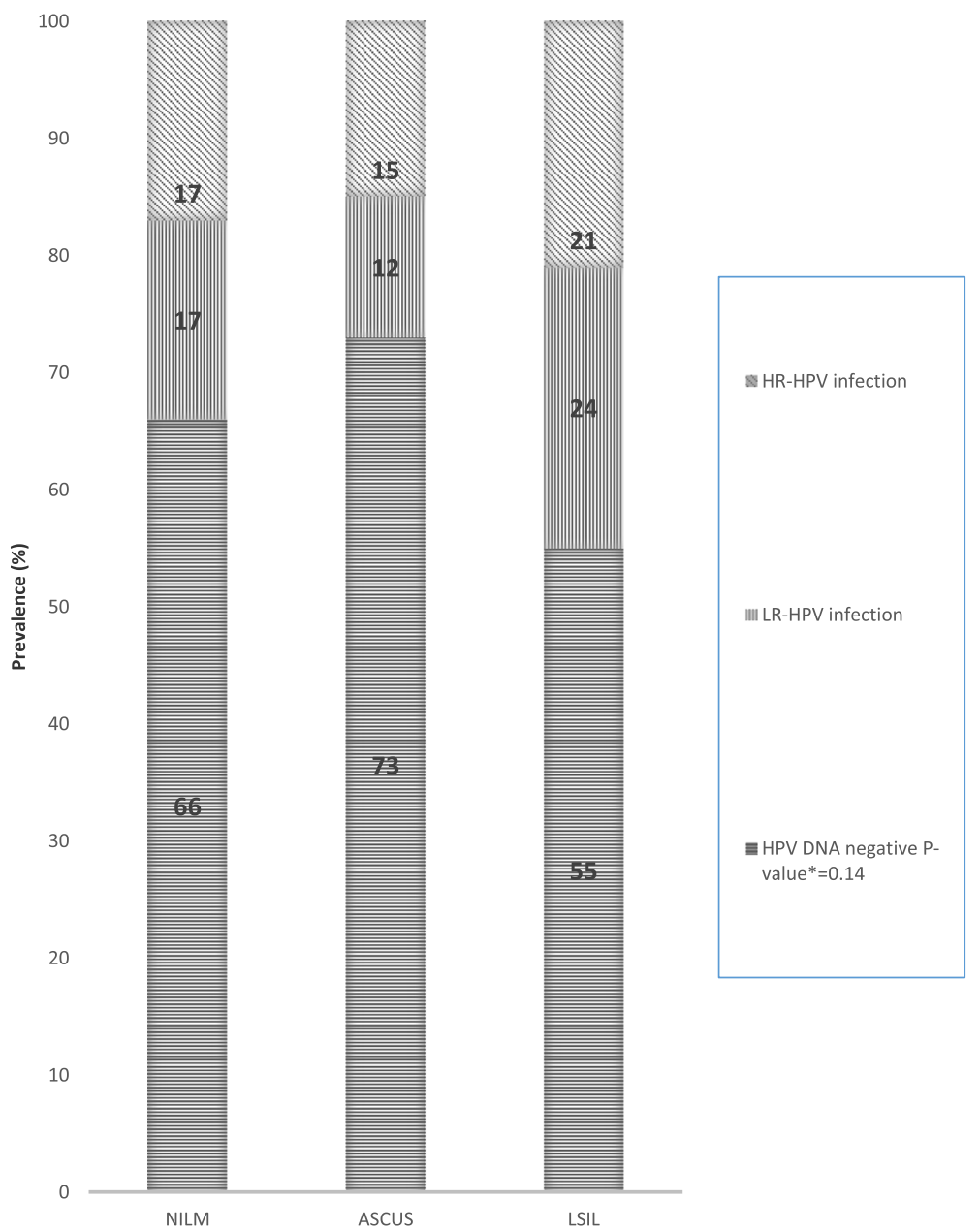

Fig. 2 Prevalence of intra-anal HPV DNA infection by cytology grade. *P-value for the association between HR-HPV prevalence and cytology grade

abnormal cytology in age-adjusted models. Infection with type 16 was marginally associated with abnormal anal cytology $(\mathrm{aOR}=3.30 ; 95 \% \mathrm{CI}=0.87-12.51$; $p=0.08)$. No association was observed between presence of AGWs and abnormal anal cytology. After further adjusting for marital status, CD4+ count and duration on ART, no significant associations were observed between intra-anal HPV infection and abnormal cytology (Additional file 2: Table S2). Men with alpha-9 types had 3 times the odds of having abnormal cytology compared to those without the infection $(\mathrm{OR}=3.08$, 95\%CI0.8411.35; $p=0.09$ ) and those with HPV type 16 had over 5.12 times the odds of abnormal cytology $(\mathrm{OR}=5.12$, 95\%CI0.72-36.52; $p=0.10$ ).

\section{Association between LR HPV infections, ART and HIV disease, and AGWs}

Twelve percent of all men had AGWs $(n=36$; Table 1$)$. Of these, $31 \%(n=11)$ had intra-anal HPV infection whilst 28\% $(n=10)$ had abnormal anal cytology (Table $3)$. Circumcision was associated with reduced odds of AGWs $(\mathrm{aOR}=0.33 ; 95 \% \mathrm{CI}=0.09-1.13 ; p=0.07)$. The presence of AGWs was influenced by several HIVrelated factors. Shorter duration on ART was associated with increased odds of AGWs detection, and there was evidence of an inverse dose response relationship. Relative to being on ART for $>12$ months, being on ART for $6-12$ months $(\mathrm{aOR}=3.54 ; 95 \% \mathrm{CI}=1.29-9.72 ; p=0.01)$ and $<6$ months $(\mathrm{aOR}=6.90 ; 95 \% \mathrm{CI}=1.63-29.20$; $p=0.009)$ increased the odds of AGWs. While HIV PVL was not associated with the detection of AGWs, having a lower CD4+ count was associated with a higher odds of having AGWs. Those with the lower CD4+ counts (i.e. $<200$ cells $/ \mu \mathrm{L}$ ) had the greatest risk for AGWs $(\mathrm{aOR}=5.48 ; 95 \% \mathrm{CI}=1.60-18.78 ; p=0.01$, compared to those with CD4+ >500). Men who had evidence of HIV disease control (i.e. on ART for $>6$ months with undetectable PVL and $\mathrm{CD} 4+$ count $>350$ cells $/ \mu \mathrm{L}$ ) had a 
Table 2 The socio-behavioural, clinical and HIV-related factors associated with abnormal anal cytology

\begin{tabular}{|c|c|c|c|c|c|}
\hline Characteristic & $\begin{array}{l}\text { Abnormal anal cytology } \\
N=118 \\
\mathrm{n}(\%) \text { or mean (SD) }\end{array}$ & $\begin{array}{l}\text { M } 1 \text { (Crude) } \\
\text { OR (95\% Cl) }\end{array}$ & $p$-value & $\begin{array}{l}\mathrm{M} \mathrm{2}^{\mathrm{a}} \\
\mathrm{aOR}(95 \% \mathrm{Cl})\end{array}$ & $p$-value \\
\hline Born in SA & $84(72)$ & $1.38(0.80-2.37)$ & 0.25 & $1.38(0.79-2.38)$ & 0.25 \\
\hline Single & $85(72)$ & $1.76(0.98-3.00)$ & 0.06 & $1.76(1.00-3.11)$ & 0.05 \\
\hline Employed & $83(70)$ & $0.86(0.49-1.51)$ & 0.60 & $0.86(0.48-1.55)$ & 0.62 \\
\hline Currently smokes & $35(30)$ & $1.06(0.61-1.85)$ & 0.84 & $1.06(0.61-1.85)$ & 0.84 \\
\hline Currently drinks alcohol & $63(53)$ & $1.23(0.74-2.03)$ & 0.43 & $1.23(0.74-2.05)$ & 0.42 \\
\hline Age at sexual debut & $18(3)$ & $1.02(0.94-1.10)$ & 0.70 & $1.02(0.94-1.10)$ & 0.70 \\
\hline Ever had sex with men & $8(5)$ & $1.60(0.44-5.80)$ & 0.48 & $1.60(0.44-5.86)$ & 0.47 \\
\hline$>1$ sexual partner in past 3 months & $25(21)$ & $0.90(0.49-1.67)$ & 0.75 & $0.90(0.49-1.67)$ & 0.74 \\
\hline Consistent condom use with recent partner & $77(65)$ & $1.87(0.86-4.08)$ & 0.12 & $1.86(0.86-4.12)$ & 0.12 \\
\hline Anogenital warts present & $10(8)$ & $0.67(0.29-1.55)$ & 0.34 & $0.67(0.29-1.55)$ & 0.35 \\
\hline On ART & $88(75)$ & $2.08(1.20-3.59)$ & 0.009 & $2.26(1.26-4.09)$ & 0.007 \\
\hline \multicolumn{6}{|l|}{ Duration on ART (months) } \\
\hline$>12$ & $68(58)$ & 1 & & 1 & \\
\hline $6-12$ & $16(14)$ & $1.13(0.49-2.65)$ & 0.77 & $1.01(0.43-2.41)$ & 0.97 \\
\hline$<6$ & $3(3)$ & $0.47(0.11-2.04)$ & 0.31 & $0.41(0.09-1.82)$ & 0.24 \\
\hline \multicolumn{6}{|l|}{ CD4+ count (cells/ $\mu \mathrm{L})$} \\
\hline$>500$ & $37(31)$ & 1 & & 1 & \\
\hline $351-500$ & $41(35)$ & $1.65(0.88-3.08)$ & 0.12 & $1.65(0.88-3.09)$ & 0.12 \\
\hline $200-350$ & $21(18)$ & $1.03(0.51-2.09)$ & 0.94 & $1.03(0.50-2.09)$ & 0.94 \\
\hline$<200$ & $12(10)$ & $2.27(0.81-6.32)$ & 0.12 & $2.26(0.81-6.32)$ & 0.12 \\
\hline Undetectable PVL ( $<40$ copies/ml) & $51(43)$ & $0.64(0.38-1.10)$ & 0.10 & $0.63(0.36-1.09)$ & 0.09 \\
\hline Controlled HIV disease $^{\mathrm{b}}$ & $33(28)$ & $1.38(0.77-2.48)$ & 0.28 & $1.35(0.81-2.36)$ & 0.30 \\
\hline
\end{tabular}

Abnormal cytology included ASCUS and LSIL. M2 ${ }^{\mathrm{a}}$ : Adjusted for age. ${ }^{\mathrm{b}}$ : On ART for $>6$ months, CD4+ $>350$ and undetectable PVL

reduced likelihood for detection of $\mathrm{AGWs}(\mathrm{aOR}=0.22$; 95\% CI $=1.20-0.79 ; p=0.02$ ).

As shown in Additional file 3: Table S3, the detection of any LR-HPV infection was strongly associated with presence of AGWs in age-adjusted models $(\mathrm{aOR}=41.28$; $95 \% \mathrm{CI}=13.57-125.62 ; p<0.001)$. MLWH with more than one LR-HPV type were also more likely to have AGWs $(\mathrm{aOR}=4.14 ; 95 \% \mathrm{CI}=1.60-10.69 ; p=0.003)$ than those with one LR-HPV type or less. Typespecific infections were also strongly associated with the presence of AGWs. Having type $6(\mathrm{aOR}=3.97$; $95 \% \mathrm{CI}=1.50-10.62 ; p=0.006)$, type $55(\mathrm{aOR}=3.10$; $95 \% \mathrm{CI}=1.19-8.07 ; p=0.02)$ or type $61(\mathrm{aOR}=2.78$; $95 \% \mathrm{CI}=1.28-6.32 ; p=0.01$ ) were all strongly associated with AGWs. After further adjusting for circumcision status, CD4+ count and duration on ART (Additional file 3: Table S3), similar associations with M2 were observed except that associations with types 55 and 61 became insignificant (effect sizes of associations were similar to M1 and M2). Type 11 was associated with AGWs in M3 only $(\mathrm{aOR}=11.50,95 \% \mathrm{CI}=1.10-119.18$; $p=0.04)$.

\section{Discussion}

In this study we estimated the prevalence of anogenital HPV infection and associated disease, their risk factors and uptake of anal swabbing using baseline data from a cohort of 304 MLWH. The prevalence of genital and anal HPV infection was relatively high at $79 \%$ and $39 \%$ respectively. This was matched by a $12 \%$ prevalence of AGW and almost half having anal cytological abnormalities.

The burden of genital HPV infection was consistent with findings from other studies among MLWH in South Africa, as well as in other settings [6, 42]. For example, the prevalence of genital HPV infection among 161 MLWH in Cape Town, South Africa was 77\% [42]. Similarly, the levels of intra-anal HPV infection in this population of predominantly men who have sex with women mirrors the findings of other studies of anal infection (ranging between 36 and 59\%) among MLWH without a history of receptive anal intercourse [43-45]. These infections could be due to non-sexual transfer of HPV between the male genitals and the anal canal which can occur via self-inoculation (i.e. direct transfer from genitals to the anus), contaminated fingers and other 
Table 3 The socio-behavioural, clinical and HIV-related factors associated with anogenital warts

\begin{tabular}{|c|c|c|c|c|c|}
\hline Characteristic & $\begin{array}{l}\text { AGW detected } \\
N=36 \\
n(\%) \text { or mean (SD) }\end{array}$ & $\begin{array}{l}\text { M } 1 \text { (Crude) } \\
\text { OR (95\% Cl) }\end{array}$ & $p$-value & $\begin{array}{l}\text { M2 }{ }^{a} \\
\text { OR }(95 \% C l)\end{array}$ & $p$-value \\
\hline Born in SA & $27(75)$ & $1.44(0.65-3.20)$ & 0.36 & $1.60(0.71-3.58)$ & 0.25 \\
\hline Marital status (Single) & $29(80)$ & $2.00(0.83-4.81)$ & 0.12 & $1.71(0.69-4.21)$ & 0.24 \\
\hline Employed & $26(72)$ & $1.20(0.54-2.67)$ & 0.66 & $1.02(0.45-2.30)$ & 0.97 \\
\hline Currently smokes & $12(33)$ & $1.13(0.54-2.38)$ & 0.74 & $1.16(0.55-2.44)$ & 0.70 \\
\hline Currently drinks alcohol & $20(56)$ & $1.18(0.58-2.41)$ & 0.65 & $1.09(0.53-2.24)$ & 0.82 \\
\hline Age at sexual debut & $18(3)$ & $0.99(0.89-1.11)$ & 0.91 & $1.00(0.89-1.13)$ & 0.93 \\
\hline Ever had sex with men & $1(3)$ & $0.52(0.07-4.06)$ & 0.53 & $0.48(0.06-3.80)$ & 0.49 \\
\hline$>1$ sexual partners in past 3 months & $8(22)$ & $0.89(0.38-2.04)$ & 0.78 & $0.82(0.35-1.92)$ & 0.65 \\
\hline Consistent condom use with recent partner & $25(69)$ & $1.81(0.52-6.31)$ & 0.35 & $2.16(0.61-7.70)$ & 0.23 \\
\hline Circumcised & $3(8)$ & $0.32(0.10-1.09)$ & 0.06 & $0.33(0.09-1.13)$ & 0.07 \\
\hline On ART & $26(72)$ & $1.47(0.68-3.19)$ & 0.32 & $2.19(0.94-5.07)$ & 0.07 \\
\hline \multicolumn{6}{|l|}{ Duration on ART (months) } \\
\hline$>12$ & $14(39)$ & 1 & & 1 & \\
\hline $6-12$ & $8(22)$ & $4.03(1.50-10.81)$ & 0.006 & $3.54(1.29-9.72)$ & 0.01 \\
\hline$<6$ & $4(11)$ & $8.06(1.94-33.50)$ & 0.004 & $6.90(1.63-29.20)$ & 0.009 \\
\hline \multicolumn{6}{|l|}{ CD4+ count (cells/ML) } \\
\hline$>500$ & $7(19)$ & 1 & & 1 & \\
\hline $351-500$ & $10(28)$ & $1.72(0.63-4.71)$ & 0.29 & $1.62(0.58-4.49)$ & 0.93 \\
\hline $200-350$ & $12(33)$ & $3.68(1.36-9.95)$ & 0.01 & $4.34(1.57-12.07)$ & 0.01 \\
\hline$<200$ & $6(17)$ & $4.32(1.32-14.25)$ & 0.02 & $5.48(1.60-18.78)$ & 0.01 \\
\hline Undetectable PVL (<40 copies/ml) & $11(31)$ & $0.65(0.31-1.39)$ & 0.26 & $0.77(0.35-1.68)$ & 0.51 \\
\hline Controlled HIV disease $^{b}$ & $3(8)$ & $0.25(0.08-0.85)$ & 0.03 & $0.22(0.12-0.79)$ & 0.02 \\
\hline Cytological abnormalities & $10(28)$ & $0.67(0.29-1.55)$ & 0.35 & $0.67(0.29-1.59)$ & 0.37 \\
\hline
\end{tabular}

$\mathrm{M}^{\mathrm{a}}{ }^{\mathrm{a}}$ : Adjusted for age. PVL plasma viral load. ${ }^{\mathrm{b}}$ : On ART for $>6$ months, CD4+ > 350 and undetectable PVL

inanimate objects [46-49]. The fairly high concordance between genital and anal HPV infections observed in our study supports the concept of non-sexual transfer.

We showed that intra-anal swabs were acceptable to African MLWH, with the large majority agreeing to sampling. We did not observe any HSIL in this population of predominantly men who have sex with women who were in reasonably good health as evidenced by high a median $\mathrm{CD} 4+$ count, and the proportion of participants with controlled HIV disease. A considerable proportion of anal cytology specimens were, however, ASCUS or LSIL, which is reflective of prevalent HPV infection. In terms of the natural history of HPV infection, low-grade lesions (ASCUS and LSIL) represent the acute phase of infection with cellular proliferation [50], whilst HSIL is more representative of established disease (AIN). These findings are similar to other cohorts of MLWH which show that on average $50 \%$ of anal smears are NILM, $30-40 \%$ are LSIL and typically less than $5 \%$ are HSIL [51, 52].

It is worth noting that in the current study, being on ART was associated with cytological abnormalities. This could be because this study is cross sectional and we cannot comment on the temporal nature of events, but most likely patients with worse immune function are more likely to have anal disease and to have recently initiated onto therapy. However, the duration on ART, CD4 + count and virological control status were not linked with cytological abnormalities, and the association between ART and cytological abnormalities should be closely examined during longitudinal follow-up. Moreover, given that men infected with more than $1 \mathrm{HR}$ type and at least one alpha- 9 type (i.e. types $16,31,33,35,52$ and 58) had a 2 to 4-fold-increased likelihood of having anal cytological abnormalities, it would be important to prospectively monitor men with these infections to better understand the factors that influence disease progression in this population and how ART interacts with these processes.

Levels of AGWs in our study were within the upper range of the AGW prevalence among men in Southern Africa, where studies have reported prevalence of between 2 and 14\% [27, 53]. Men with genital HPV 6 infections were almost 4 times more likely to have 
prevalent AGWs in age-adjusted models, an almost identical odds ratio of this association that was noted in a study of 245 MLWH in Australia who have sex with men [54]. Overall, the study findings provide a compelling argument for the use of the HPV vaccination as primary prevention for AGWs in men, particularly those living with HIV. HPV vaccines are safe and immunogenic in HIV-positive individuals [55]. Despite the overall high HPV burden among HIV-infected individuals, the majority of them, both in this study and others, do not have infection with HPV types included in current HPV vaccines, and thus could benefit from vaccination. For example, the DNA prevalence of the vaccine preventable types 16 and 18 among HIV-positive women were $16 \%$ and $11 \%$ respectively in a study in Puerto Rico [56]. This means that more than $80 \%$ could potentially benefit from HPV vaccination as primary prevention. Moreover, rapidly accruing evidence also indicates that the vaccine is also beneficial as a secondary prevention strategy for the prevention of recurrent anal neoplasia and recurrent AGWs [57-59].

A lower CD4+ count was associated with an increased risk for AGWs, consistent with reports from other studies $[26,60]$. This observation is primarily attributed to immune dysfunction, which impairs the clearance of HPV infections [24, 28]. In this study, a longer duration on ART (i.e. $>12$ months), and not the ART status per se, was associated with a reduced likelihood of prevalent AGWs. This is consistent with data showing that some time is required for immune reconstitution to occur before the clinical effects of ART are observed [61]. The multivariate analysis performed in the study (M3) illustrates the important role of age, marital status, duration on ART, CD4+ count with abnormal cytology as $>1 \mathrm{HR}$ type and alpha 9 types became insignificant in this model.

Limitations of the study include its cross-sectional design, which means that causality cannot be inferred about the associations observed. The absence of a sampling frame for the population made it hard to obtain a random, representative sample of the target population. We recruited from both community and healthcare settings in an attempt to increase the representativeness of the sample. Nevertheless, men in clinical settings and those in the community who accept to take part in a study may have different health seeking behaviours and medical conditions than other men. Plausibly, such differences could both under- or overestimate HPV prevalence and disease, and thus caution needs to be applied when interpreting and generalising the prevalence estimates. Also, the low numbers of MSM in the study diminished the ability to detect associations between this exposure and the study outcomes. Having had sex with men may have been under-reported, given that the behaviour remains stigmatised. It is, however, also possible that under-reporting did not occur as other evidence also indicates that HPV infection is common in men who have sex with women and who do not report receptive anal intercourse [2,62].

In terms of methods, visual inspection for AGWs detection was done without histological confirmation, making it possible that other conditions (e.g. penile intraepithelial neoplasia) could have been misclassified as warts. Similarly, we used conventional anal smears which could have misclassified cytological outcomes. We did not have access to high resolution anoscopy (HRA) and guided biopsy, the gold standard for pathological diagnosis. The study, however, used the Roche Linear Array for HPV DNA testing and genotyping, which has greater accuracy and specificity than other commonly used assays, such as INNO-LiPA and reverse hybridization [63]. However, with use of Roche Linear Array, the potential HR types: 26, 53, 66 and HR types 73, 82 may be missed as these are classified as LR in that test, while INNO-LiPA classifies them as potential HR and HR types respectively. Nevertheless, despite these limitations, the study does contribute important data on the prevalence of anogenital HPV infection and associated disease, including the impact of ART among MLWH. Longitudinal data will more fully explore the incidence, persistence, clearance or regression of anogenital HPV infection and associated disease, and the impact of ART so as to inform guidelines on preventing and treating HPV associated disease in this key population.

\section{Conclusions}

In this African inner-city setting among MLWH who are predominantly men who have sex with women, anogenital HPV infection is very common, associated disease is also relatively frequent, but no cases of severe anal dysplasia were noted. The study does not support the use of screening for anal dysplasia in this population since we did not detect any high-grade anal lesions, and as there would be substantial laboratory and programmatic challenges involved in such a programme. HPV vaccination would be of benefit for the primary and secondary prevention of both AGWs and HR-HPV infections, even though it is still not clear whether this translates into a reduction of anal disease.

\section{Additional files}

Additional file 1: Table S1. Distribution of the HPV genotypes according to the cytological diagnosis. (DOC 66 kb)

Additional file 2: Table S2. Associations between intra anal HPV infection and abnormal cytology. (DOC 57 kb)

Additional file 3: Table S3. Associations between genital HPV infection and anogenital warts. (DOC $57 \mathrm{~kb}$ ) 


\section{Abbreviations}

AGWs: anogenital warts; AIN: anal intraepithelial neoplasia; ART: antiretroviral therapy; ASC-H: atypical squamous cells-high grade lesions cannot be ruled out; ASCUS: atypical squamous cells of undetermined significance; HPV: human papillomavirus; HR: high-risk; HRA: High Resolution Anoscopy; HSIL: high-grade squamous intraepithelial lesion; IQR: interquartile range; LMICs: low- and middle-income countries; LR: low-risk; LSIL: low-grade squamous intraepithelial lesion; MLWH: men living with HIV; MSM: men who have sex with men; NHLS: National Health Laboratory Service; NILM: negative for intraepithelial malignancy; pHR: possible High Risk; PVL: plasma viral load; SD: standard deviation; SSA: sub-Saharan Africa; STI: sexually transmitted infection

\section{Acknowledgments}

We would like to thank the study participants, and the clinical, laboratory, field worker, data management and administrative staff who worked on this project.

\section{Funding}

The authors of this publication received funding from European and Developing Countries Clinical Trial Partnership (EDTCP) (project code TA.10.40200.034). However, EDTCP cannot accept any responsibility for information or views expressed here. AC received funding from the Consortium of Advanced Research Training in Africa (CARTA). CARTA is jointly led by the African Population and Health Research Centre and the University of the Witwatersrand and funded by the Wellcome Trust (UK) (Grant No: 087547/Z/08/Z), the Department for International Development (DfID) under the development partnerships in Higher Education (DelPHE), the Carnegie Cooperation of New York (Grant No: B 8606), the Ford Foundation (Grant No: 1100-0399), Google Org (Grant No: 191,994), Sida (Grant No: 54,100,029) and MacArthur Foundation (Grant No: 10-95,915-000INP). SDM and PP were supported in part by a grant from the UK Department for International Development to the STRIVE Research Programme Consortium (Ref: Po 5244). However, the views expressed do not necessarily reflect the Department's official policies. This research was supported by a Cancer Association of South Africa (CANSA) grant. WRHI Research Capacity Building funds were used to fund the publications charges for the supplement.

\section{Availability of data and materials}

The datasets generated during and/or analysed during the current study are not publicly available as they contain longitudinal data which are still to be published. The datasets are, however, available from the corresponding author on reasonable request.

\section{Authors' contributions}

SDM and PM conceptualised and designed the study. AC and SDM developed the study instruments and sought ethical approval. AC and SDM supervised the data collection. PM analysed the conventional smears whilst ETM conducted the HPV DNA testing. LC and PTP conducted the data analysis. AC wrote the first draft of the manuscript and all authors critically revised the draft and gave approval of the final manuscript.

\section{Competing interests}

The authors declare they have no competing interests.

\section{Consent for publication}

Not applicable.

\section{Ethics approval and consent to participate}

The protocol for the study was approved by the Wits Human Research Ethics Committee (Reference number: M111191). Written, informed consent was obtained from all study participants after full explanation of the study objectives and testing procedures.

\section{About this supplement}

This article has been published as part of BMC Public Health Volume 17 Supplement 3, 2017: Urban Health at the Edge: A Series on Reproductive Health and HIV in inner-city Johannesburg. The full contents of the supplement are available online at https://bmcpublichealth.biomedcentral.com/articles/supplements/volume-17-supplement-3

\section{Author details}

'Wits Reproductive Health and HIV Institute (WRHI), Faculty of Health Sciences, University of the Witwatersrand, Johannesburg, South Africa. ${ }^{2}$ National Institute for Communicable Diseases, National Health Laboratory Service, Johannesburg, South Africa. ${ }^{3}$ Department of Anatomical Pathology, Cytology Unit, University of the Witwatersrand, Johannesburg, South Africa. ${ }^{4}$ London School of Hygiene and Tropical Medicine, London, UK.

Published: 4 July 2017

\section{References}

1. Gross G, Pfister H. Role of human papillomavirus in penile cancer, penile intraepithelial squamous cell neoplasias and in genital warts. Med Microbiol Immun. 2004;193:35-44.

2. Delany-Moretlwe S, Chikandiwa A, Gibbs J. Human papillomavirus infection and disease in men: impact of HIV. Southern African J HIV Med. 2013;14(4): 183-8.

3. Smith JS, Gilbert PA, Melendy A, Rana RK, Pimenta JM. Age-specific prevalence of human papillomavirus infection in males: a global review. J Adolesc Health. 2011;48(6):540-52.

4. Chin-Hong PV, Palefsky JM. Natural history and clinical management of anal human papillomavirus disease in men and women infected with human immunodeficiency virus. Clin Infect Dis. 2002;35(9):1127-34

5. Moscicki A-B, Schiffman M, Burchell A, Albero G, Giuliano A, Goodman MT, Kjaer SK, Palefsky J. Updating the natural history of human papillomavirus and anogenital cancers. Vaccine. 2012;30(0 5):F24-33.

6. Machalek DA, Poynten M, Jin F, Fairley CK, Farnsworth A, Garland SM, Hillman RJ, Petoumenos K, Roberts J, Tabrizi SN, et al. Anal human papillomavirus infection and associated neoplastic lesions in men who have sex with men: a systematic review and meta-analysis. Lancet Oncol. 2012; 13(5):487-500

7. De Vuyst H, Clifford G, Li N, Franceschi S. HPV infection in Europe. Eur J Cancer. 2009:45(15):2632-9.

8. Forman D, de Martel C, Lacey CJ, Soerjomataram I, Lortet-Tieulent J, Bruni L, Vignat J, Ferlay J, Bray F, Plummer M, et al. Global burden of human papillomavirus and related diseases. Vaccine. 2012;20(30):055.

9. Dunne EF, Nielson CM, Stone KM, Markowitz LE, Giuliano AR. Prevalence of HPV infection among men: a systematic review of the literature. J Infect Dis. 2006;194(8):1044-57.

10. de Villiers EM, Fauquet C, Broker TR, Bernard HU, zur Hausen H. Classification of papillomaviruses. Virology. 2004;324(1):17-27.

11. Jeynes C, Chung MC. Challenor R: 'Shame on you'-the psychosocial impact of genital warts. Int J STD AIDS. 2009;20(8):557-60

12. Wiley DJ, Douglas J, Beutner K, Cox T, Fife K, Moscicki AB, Fukumoto L. External genital warts: diagnosis, treatment, and prevention. Clin Infect Dis. 2002;35(Suppl 2):S210-24.

13. Insinga RP, Dasbach EJ, Elbasha EH. Assessing the annual economic burden of preventing and treating anogenital human papillomavirus-related disease in the US: analytic framework and review of the literature. PharmacoEconomics. 2005:23(11):1107-22.

14. Ng'ayo MO, Bukusi E, Rowhani-Rahbar A, Koutsky LA, Feng Q, Kwena ZA, Holmes KK. Epidemiology of human papillomavirus infection among fishermen along Lake Victoria shore in the Kisumu District, Kenya. Sex Transm Infect. 2008;84(1):62-6.

15. Auvert B, Sobngwi-Tambekou J, Cutler E, Nieuwoudt M, Lissouba P, Puren A Taljaard D. Effect of male circumcision on the prevalence of high-risk human papillomavirus in young men: results of a randomized controlled trial conducted in Orange farm, South Africa. J Infect Dis. 2009;199(1):14-9.

16. Smith JS, Moses S, Hudgens M, Parker CB, Maclean I, Ndinya-achola JO, Snijders PJF, Chris JLM, Bailey RC. Increased risk of HIV acquisition among Kenyan men with human papillomavirus infection. J Infect Dis. 2010;201: 1677-85.

17. Müller EE, Chirwa TF, Da L. Human papillomavirus (HPV) infection in heterosexual South African men attending sexual health services: associations between HPV and HIV serostatus. Sex Transm Infect. 2010;86: $175-80$

18. Veldhuijzen NJ, Dhont N, Vyankandondera J, Gasarabwe A, Busasa R, Crucitti T, van de Wijgert JH. Prevalence and concordance of HPV, HIV, and HSV-2 in heterosexual couples in Kigali, Rwanda. Sex Transm Dis. 2012;39(2):128-35.

19. Olesen TB, Iftner T, Mwaiselage J, Kahesa C, Rasch V, Ngoma T, Munk C, Kjaer SK. Prevalence and type distribution of human papillomavirus among 
1813 men in Tanzania and the relationship to HIV status. Sex Transm Dis. 2013:40(7):592-8.

20. Mbulawa ZZ, Marais DJ, Johnson LF, Coetzee D, Williamson AL. Impact of human immunodeficiency virus on the natural history of human papillomavirus genital infection in South African men and women. J Infect Dis. 2012;206

21. Tobian AAR, Kigozi G, Gravitt PE, Xiao C, Serwadda D, Eaton KP, Kong X, Wawer MJ, Nalugoda F, Quinn TC, et al. Human papillomavirus incidence and clearance among HIV-positive and HIV-negative men in Rakai, Uganda. AIDS (London, England). 2012;26(12):1555-65.

22. Backes DM, Snijders PJ, Hudgens MG, Bailey RC, Bogaarts M, Agot K, Agingu W, Moses S, Meijer CJ, Smith JS. Sexual behaviour and less frequent bathing are associated with higher human papillomavirus incidence in a cohort study of uncircumcised Kenyan men. Sex Transm Infect. 2013;89(2):148-55.

23. Shiels MS, Pfeiffer RM, Gail MH, Hall HI, Li J, Chaturvedi AK, Bhatia K, Uldrick TS, Yarchoan R, Goedert JJ, et al. Cancer burden in the HIV-infected population in the United States. J Natl Cancer Inst. 2011;103(9):753-62.

24. Nyitray AG, Smith D, Villa L, Lazcano-Ponce E, Abrahamsen M, Papenfuss M, Giuliano AR. Prevalence of and risk factors for anal human papillomavirus infection in men who have sex with women: a cross-national study. J Infect Dis. 2010;201(10):1498-508.

25. Beachler DC, Weber KM, Margolick JB, Strickler HD, Cranston RD, Burk RD, Wiley DJ, Minkoff H, Reddy S, Stammer EE, et al. Risk factors for oral HPV infection among a high prevalence population of HIV-positive and at-risk HIV-negative adults. Cancer Epidemiol Biomarkers Prev. 2012;21(1):122-33.

26. Silverberg MJ, Ahdieh L, Munoz A, Anastos K, Burk RD, Cu-Uvin S, Duerr A, Greenblatt RM, Klein RS, Massad S, et al. The impact of HIV infection and immunodeficiency on human papillomavirus type 6 or 11 infection and on genital warts. Sex Transm Dis. 2002;29(8):427-35.

27. Neme S, Wahome E, Mwashigadi G, Thiong'o AN, Stekler JD, Wald A, Sanders EJ, Graham SM. Prevalence, incidence, and clearance of Anogenital warts in Kenyan men reporting high-risk sexual behavior, including men who have sex with men. Open Forum Infect Dis. 2015;2(2):ofv070.

28. Vesely MD, Kershaw MH, Schreiber RD, Smyth MJ. Natural innate and adaptive immunity to cancer. Annu Rev Immunol. 2011;29:235-71.

29. Piketty C, Cochand-Priollet B, Lanoy E, Si-Mohamed A, Trabelsi S, Tubiana R, Girard PM, Weiss L, Costagliola D. Lack of regression of anal squamous intraepithelial lesions despite immune restoration under CART. AIDS. 2013;27(3):401-6.

30. Borghetti A, Cattani P, Maria G, D'Onghia S, Santangelo R, Marchetti S, Farina S, Cauda R, De Luca A, Di Giambenedetto S. Prevalence, incidence and predictors of anal high-risk HPV infections and cytological abnormalities in HIV-infected individuals. J Inf Secur. 2015;70(1):60-71.

31. Giuliano ARPJ, Goldstone S, Moreira ED Jr, Penny ME, Aranda C, et al. Efficacy of quadrivalent HPV vaccine against HPV infection and disease in males. N Engl J Med. 2011;364:401-11.

32. Ali H, Donovan B, Wand H, Read TR, Regan DG, Grulich AE, Fairley CK, Guy RJ. Genital warts in young Australians five years into national human papillomavirus vaccination programme: national surveillance data. BMJ. 2013;346:f2032.

33. Simbayi L, Shisana O, Rehle T, Onoya D, Jooste S, Zungu N, Zuma K. South African national HIV prevalence, incidence and behaviour survey, 2012. Pretoria: Human Sciences Research Council; 2014.

34. Department of Health South Africa. The South African Antiretroviral Treatment Guidelines. 2013. [ http://www.kznhealth.gov.za/medicine/2013 art_guidelines.pdf]. Accessed 26 Mar 2016.

35. Weaver BA, Feng Q, Holmes KK, Kiviat N, Lee SK, Meyer C, Stern M, Koutsky $L A$. Evaluation of genital sites and sampling techniques for detection of human papillomavirus DNA in men. J Infect Dis. 2004;189(4):677-85.

36. National Department of Health. National consolidated guidelines for the prevention of mother-to-child transmission of HIV (PMTCT) and the management of HIV in children, adolescents and adults. Edited by Health NDoH. Pretoria; 2014. [http://www.sahivsoc.org/Files/ ART\%20Guidelines\%2015052015.pdf]. Accesseed 26 Mar 2016.

37. Bouvard V, Baan R, Straif K, Grosse Y, Secretan B, El Ghissassi F, BenbrahimTallaa L, Guha N, Freeman C, Galichet L, Cogliano V, on behalf of the WHO International Agency for Research on Cancer Monograph Working Group. A review of human carcinogens - part B: biological agents. Lancet Oncol. 2009;10:321-2

38. Solomon D. The Bethesda System for Reporting Cervical Cytology: Definitions, Criteria, and Explanatory Notes. 2nd edition. Edited by Nayar R, Wilbur D. Geneva: Springer; 2001.
39. Ingles DJ, Lin H-Y, Fulp WJ, Sudenga SL, Lu B, Schabath MB, Papenfuss MR, Abrahamsen ME, Salmeron J, Villa LL, et al. An analysis of HPV infection incidence and clearance by genotype and age in men: the HPV infection in men (HIM) study. Papillomavirus Res. 2015;1:126-35.

40. Colón-López V, Ortiz AP, Del Toro-Mejías L, Clatts MC, Palefsky JM. Epidemiology of anal HPV infection in high-risk men attending a sexually transmitted infection Clinic in Puerto Rico. PLoS One. 2014;9(1):e83209.

41. StataCorp: Stata statistical software, release 12. College Station, TX: StataCorp LP; 2012.

42. Mbulawa ZZA, Coetzee D, Williamson A-L. Human papillomavirus prevalence in South African women and men according to age and human immunodeficiency virus status. BMC Infect Dis. 2015;15(1):1-11.

43. Piketty C, Darragh TM, Costa MD, Bruneval P, Heard I, Kazatchkine MD, Palefsky JM. High prevalence of anal human Papillomavirus infection and anal cancer precursors among HIV-infected persons in the absence of anal intercourse. Ann Intern Med. 2003;138(6):453-9.

44. Conley L, Bush T, Darragh TM, Palefsky JM, Unger ER, Patel P, Kojic EM, CuUvin S, Martin H, Overton ET, et al. Factors associated with prevalent abnormal anal cytology in a large cohort of HIV-infected adults in the United States. J Infect Dis. 2010;202(10):1567-76.

45. Lee $\mathrm{CH}$, Lee $\mathrm{SH}$, Lee $\mathrm{S}$, Cho H, Kim K-H, Lee JE. Jung EJ, lee Sj, Kim EJ, Kim $\mathrm{KH}$ et al: anal human Papillomavirus infection among HIV-infected men in Korea. PLoS One. 2016;11(8):e0161460.

46. Nyitray AG. The epidemiology of anal human papillomavirus infection among women and men having sex with women. Sex Health. 2012;9(6): $538-46$.

47. Hernandez BY, Wilkens $L R$, Zhu X, Thompson P, McDuffie K, Shvetsov YB, Kamemoto LE, Killeen J, Ning L, Goodman MT. Transmission of human Papillomavirus in heterosexual couples. Emerg Infect Dis. 2008;14(6):888-94.

48. Ferenczy A, Bergeron C, Richart RM. Human papillomavirus DNA in fomites on objects used for the management of patients with genital human papillomavirus infections. Obstet Gynecol. 1989;74(6):950-4.

49. Partridge JM, Hughes JP, Feng $Q$, Winer RL, Weaver BA, Xi LF, Stern ME, Lee SK, O'Reilly SF, Hawes SE, et al. Genital human papillomavirus infection in men: incidence and risk factors in a cohort of university students. J Infect Dis. 2007;196(8):1128-36.

50. Kines RC, Thompson CD, Lowy DR, Schiller JT, Day PM. The initial steps leading to papillomavirus infection occur on the basement membrane prior to cell surface binding. Proc Natl Acad Sci U S A. 2009;106(48):20458-63.

51. Torres M, Gonzalez C, del Romero J, Viciana P, Ocampo A, RodriguezFortunez P, Masia M, Blanco JR, Portilla J, Rodriguez C, et al. Anal human papillomavirus genotype distribution in HIV-infected men who have sex with men by geographical origin, age, and cytological status in a Spanish cohort. J Clin Microbiol. 2013;51(11):3512-20.

52. Darwich L, Canadas MP, Videla S, Coll J, Pinol M, Cobarsi P, Molina-Lopez RA, Vela S, Garcia-Cuyas F, Llatjos M, et al. Condylomata, cytological abnormalities and human papillomavirus infection in the anal canal in HIVinfected men. HIV Med. 2012;13(9):549-57.

53. Banura C, Mirembe FM, Orem J, Mbonye AK, Kasasa S, Mbidde EK. Prevalence, incidence and risk factors for anogenital warts in sub Saharan Africa: a systematic review and meta analysis. Infect Agent Cancer. 2013;8(1):27.

54. Poynten IM, Waterboer T, Jin F, Templeton DJ, Prestage G, Donovan B, Pawlita M, Fairley CK, Garland SM, Grulich AE. Human papillomavirus types 6 and 11 seropositivity: risk factors and association with ano-genital warts among homosexual men. J Inf Secur. 2013;66(6):503-11.

55. Kojic EM, Kang M, Cespedes MS, Umbleja T, Godfrey C, Allen RT, Firnhaber C, Grinsztejn B, Palefsky JM, Webster-Cyriaque JY, et al. Immunogenicity and safety of the Quadrivalent human Papillomavirus vaccine in HIV-1-infected women. Clin Infect Dis. 2014;59(1):127-35.

56. Fife KH, Wu JW, Squires KE, Watts DH, Andersen JW, Brown DR. Prevalence and persistence of cervical human Papillomavirus infection in HIV-positive women initiating highly-active antiretroviral therapy. J Acquir Immune Defic Syndr. 2009;51(3, 274):-282.

57. Deshmukh AA, Chhatwal J, Chiao EY, Nyitray AG, Das P, Cantor SB. LongTerm Outcomes of Adding HPV Vaccine to the Anal Intraepithelial Neoplasia Treatment Regimen in HIV-Positive Men Who Have Sex with Men. Clinical Infectious Diseases. 2015;61(10):1527-35.

58. Swedish KA, Factor SH, Goldstone SE. Prevention of recurrent high-grade anal neoplasia with quadrivalent human papillomavirus vaccination of men who have sex with men: a nonconcurrent cohort study. Clin Infect Dis. 2012;54(7):891-8. 
59. Swedish KA, Goldstone SE. Prevention of anal Condyloma with Quadrivalent human Papillomavirus vaccination of older men who have sex with men. PLoS One. 2014;9(4):e93393.

60. Low AJ, Clayton T, Konate I, Nagot N, Ouedraogo A, Huet C, DidelotRousseau M-N, Segondy M, Van de Perre P, Mayaud P: Genital warts and infection with human immunodeficiency virus in high-risk women in Burkina Faso: a longitudinal study. BMC Infect Dis 2011, 11(1):1-9.

61. Wilson EMP, Sereti I. Immune restoration after antiretroviral therapy: the pitfalls of hasty or incomplete repairs. Immunol Rev. 2013;254(1):343-54.

62. Abramowitz L, Benabderrahmane D, Ravaud P, Walker F, Rioux C, Jestin C, Bouvet E, Soule JC, Leport C, Duval X. Anal squamous intraepithelial lesions and condyloma in HIV-infected heterosexual men, homosexual men and women: prevalence and associated factors. AIDS. 2007;21(11):1457-65.

63. Steinau M, Onyekwuluje JM, Scarbrough MZ, Unger ER, Dillner J, Zhou T. Performance of commercial reverse line blot assays for human Papillomavirus genotyping. J Clin Microbiol. 2012;50(5):1539-44.

Submit your next manuscript to BioMed Central and we will help you at every step:

- We accept pre-submission inquiries

- Our selector tool helps you to find the most relevant journal

- We provide round the clock customer support

- Convenient online submission

- Thorough peer review

- Inclusion in PubMed and all major indexing services

- Maximum visibility for your research

Submit your manuscript at www.biomedcentral.com/submit
Biomed Central 